\title{
JARINGAN KOMUNIKASI KEPALA DESA DALAM INOVASI PROGRAM PEMBANGUNAN
}

\author{
Fikar Damai Setia Gea \\ Program Magister Ilmu Komunikasi, FISIP, Universitas Andalas \\ Jl. Universitas Andalas, Limau Manis, Pauh, Padang, Sumatera Barat, 25163, Indonesia \\ No. Telp./HP: 081362384531 \\ E-mail: fikar_g@yahoo.co.id
}

Naskah dikirim pada tanggal 26 Oktober 2017, direvisi tanggal 26 Januari 2018, disetujui tanggal 13 April 2018

\section{COMMUNICATION NETWORK OF VILLAGE HEADS IN INNOVATION OF DEVELOPMENT PROGRAM}

\begin{abstract}
This research aims to analyze the flow of information that occurs in the network, analyze the network structure, identify patterns of relationships within the network, identify the role of actors in the network and detect key actors in the village head communications network in Nias Regency. The research approach used is a quantitative descriptive method. A total of 105 village heads were selected as research samples with snowball sampling technique. Data were collected by using questionnaire research instrument. Data analysis technique used is the communication network analysis. The results showed that the content of messages exchanged in the village head communication network was dominated by discussion of village fund management based on friendship ties. In parallel, the network structure of village heads in Nias Regency as a whole is categorized as a weak communication network because it limits itself to the subdivision of groups (sub regency). This condition affects the network pattern that formed is radial personal network tends to spread and open to the environment but with limited information.
\end{abstract}

Keywords: communication network, village head, development innovation, centrality.

\begin{abstract}
Abstrak. Penelitian ini bertujuan untuk menganalisis arus informasi yang terjadi dalam jaringan, menganalisis struktur jaringan, mengidentifikasi pola hubungan dalam jaringan, mengidentifikasi peranan aktor dalam jaringan, dan mendeteksi aktor kunci dalam jaringan komunikasi kepala desa di Kabupaten Nias. Pendekatan yang digunakan adalah deskriptif kuantitatif. Sebanyak 105 kepala desa yang terpilih sebagai sampel penelitian dengan teknik penarikan sampel snowball sampling. Data dikumpulkan dengan menggunakan instrumen penelitian berupa kuesioner. Teknik analisis data yang digunakan ialah analisis jaringan komunikasi. Hasil penelitian menunjukkan bahwa isi pesan yang dipertukarkan dalam jaringan komunikasi kepala desa didominasi oleh diskusi tentang pengelolaan dana desa yang didasari oleh ikatan hubungan persahabatan. Sejalan dengan itu, struktur jaringan kepala desa di Kabupaten Nias secara keseluruhan dikategorikan sebagai jaringan komunikasi yang lemah karena membatasi diri dengan sekat-sekat kelompok (kecamatan). Kondisi ini berdampak pada pola jaringan yang terbentuk adalah radial personal network cenderung menyebar dan terbuka terhadap lingkungannya namun dengan informasi yang terbatas.
\end{abstract}

Kata kunci: jaringan komunikasi, kepala desa, inovasi pembangunan, sentralitas. 


\section{PENDAHULUAN}

Jaringan komunikasi merupakan suatu pola yang teratur dari hubungan antar individu yang dapat diidentifikasi sebagai pertukaran informasi yang dialami seseorang di dalam sistem sosialnya (Berger, 2014). Sebuah jaringan komunikasi identik dengan keterhubungan di antara dua aktor atau lebih. Studi jaringan komunikasi memberi penekanan pada relasi antara satu aktor dengan aktor yang lain dalam struktur sosial tertentu. Wasserman \& Faust (1994) lebih detail menjelaskan bahwa jaringan komunikasi terdiri dari seperangkat aktor (node) dan hubungan (ties) di antara aktor. Aktor (node) dapat berupa individu, kelompok, organisasi atau masyarakat. Sedangkan hubungan (ties) mungkin terjadi di antara individu dengan individu atau terjadi di antara individu dengan kelompok tertentu, dan seterusnya.

Dalam perspektif komunikasi, hubungan di antara aktor merupakan dimensi yang sangat penting dan prinsip. Katz et al. (2004) menjelaskan bahwa melalui hubungan yang terjadi di antara aktor akan menggambarkan jenis-jenis ikatan yang muncul. Berbagai jenis ikatan yang mungkin muncul, antara lain: ikatan hubungan komunikasi (siapa berbicara kepada siapa atau siapa yang memberi informasi atau saran kepada siapa), ikatan formal (siapa yang melapor kepada siapa), ikatan afektif (siapa yang menyukai siapa atau siapa yang mempercayai siapa), ikatan kedekatan (dekat secara spasial atau secara elektronik) dan hubungan kognitif (siapa yang tahu siapa yang mengenalnya).

Jaringan komunikasi juga sangat erat kaitannya dengan inovasi. Hal ini menyangkut proses sosial bagaimana inovasi (ide, praktik-praktik, dan objekobjek baru) menjadi diketahui dan tersebar ke seluruh sistim sosial dan pada akhirnya diadopsi oleh unit-unit adopsi (Severin \& Tankard, 2009). Dalam menentukan apakah akan mengadopsi inovasi, evaluasi subjektif inovasi mengalir melalui jaringan interpersonal karena jaringan dapat berfungsi sebagai koneksi penting ke sumber informasi. Maka dalam difusi inovasi hingga pada adopsi inovasi muncul peran-peran individu dalam jaringan, yang disebut oleh (Rogers \& Kincaid, 1981) sebagai struktur komunikasi.

Dalam pandangan Rogers \& Kincaid (1981) analisis jaringan komunikasi merupakan sebuah riset untuk mengidentifikasi struktur komunikasi dalam sebuah sistem, yang mana data relasional tentang arus informasi dianalisis dengan menggunakan beberapa tipe hubungan antar personal sebagai unit analisis. Adopsi terhadap inovasi merupakan salah satu elemen penting dalam meningkatkan derajad pembangunan di desa. Proses adopsi inovasi bertujuan untuk melakukan perubahan-perubahan ke arah yang lebih baik di tengah-tengah masyarakat. Ide, praktik, dan objek-objek baru hasil adopsi diharapkan dapat memperbaiki pengetahuan dan perilaku/sikap masyarakat agar menjadi lebih maju dan berkembang dengan cepat. Oleh karena itu, setiap pemerintahan desa membutuhkan pemimpin-pemimpin yang mampu membangun jaringan dengan pihak lain untuk memobilisasi gagasangagasan baru untuk kepentingan masyarakat (Leeuwis, 2009).

Jaringan komunikasi berkontribusi penting terhadap pengembangan inovasi pembangunan terutama di perdesaan. Melalui komunikasi setiap kepala desa dapat memperoleh informasi tentang teknologi, inovasi, dan mekanisme pembangunan terbaru sebagai hasil interaksi individu masing-masing kepala desa. Pasca diterbitkannya UndangUndang Nomor 6 Tahun 2014 tentang Desa, khasanah paradigma pembangunan di Indonesia kembali diperbarui. Posisi desa menjadi lebih kuat dan kokoh secara sosial kemasyarakatan dan berdaulat secara politik dalam kerangka demokrasi desa, pengembangan ekonomi desa berbasis potensi lokal dan pembangunan 
desa secara mandiri. Paradigma baru pembangunan desa sangat berbeda dari paradigma lama dimana selama ini kewenangan desa hanya bersifat target. Desa secara mandiri dan penuh menyelenggarakan pemerintahan, pembangunan dan pemberdayaan masyarakat. Paradigma ini menggunakan asas atau prinsip umum rekognisisubsidiaritas (Mustakim, 2015).

Pembangunan desa ditujukan untuk meningkatkan kesejahteraan dan kualitas hidup masyarakat desa, dengan mendorong pembangunan desa-desa mandiri dan berkelanjutan yang memiliki ketahanan sosial, ekonomi, dan lingkungan sesuai dengan amanat UU Desa. Lie Keqiang dalam Kasali (2016) mengatakan bahwa desa harus mampu berubah dan berpikir layaknya sebuah kota yang maju dan mandiri, baik dalam partisipasi politik, struktur ekonomi, lapangan kerja, lingkungan hidup, rekreasi, menikmati fasilitas publik, kesejahteraan, dan jaminan sosial.

Desa sebagai sebuah komunitas dan subjek pembangunan diharapkan mampu mengembangkan masyarakatnya dalam sebuah proses dialog, pertukaran informasi yang dinamis, peningkatan kesadaran melalui pendidikan serta aksi pembangunan yang sedang berjalan dengan seluruh kompleksitasnya yang bertujuan menolong orang-orang yang konsen membangun komunitas dalam konteks mereka sendiri dan mewujudkannya dalam konstruksi mereka sendiri (Ife \& Tesoriero, 2008). Ruang seperti inilah kondisi ideal sebuah pemerintahan desa dimana kedudukannya menjadi pemerintahan masyarakat, hybrid antara self governing community dan local self government dengan sistem village driven development (Mustakim, 2015).

Ketika kewenangan pembangunan di perdesaan kini sepenuhnya berada di tangan para pemangku kepentingan di desa, utamanya kepala desa sebagai pemimpin tertinggi pemerintahan desa, tantangan utamanya adalah bagaimana sebuah kebijakan yang unggul untuk kepentingan publik (masyarakat desa) diambil dan pelayanan publik yang berkualitas diberikan secara optimal (Nugroho, 2015).

Dalam konteks pembangunan perdesaan di Kabupaten Nias, terdapat gap yang sangat lebar yang memisahkan antara cita-cita pembangunan perdesaan dengan realita kehidupan masyarakat, baik dilihat dari kondisi infrastruktur maupun sumber daya manusia. Berdasarkan rilis daftar daerah-daerah tertinggal di Indonesia sesuai dengan Peraturan Presiden Nomor 131 tahun 2015 tentang Penetapan Daerah Tertinggal Tahun 2015-2019, Kabupaten Nias menjadi salah satu dari empat daerah tertinggal di Sumatera Utara dari total 122 daerah tertinggal di Indonesia. Sementara berdasarkan status kemajuan dan kemandirian desa tahun 2016 yang dikeluarkan oleh Kementerian Desa, Pembangunan Daerah Tertinggal dan Transmigrasi RI menyatakan bahwa 170 desa yang ada di Kabupaten Nias masih berada pada status antara desa sangat tertinggal dan desa tertinggal.

Indikator dasar yang menunjukkan kondisi wilayah Kabupaten Nias yang masih tertinggal ialah; tingkat kemiskinan dan indeks pembangunan manusia (IPM). Berdasarkan data sebagaimana dimuat dalam Dokumen Kesejahteraan Rakyat Kabupaten Nias 2016, persentase penduduk miskin di Kabupaten Nias masih jauh lebih tinggi dibanding Sumatera Utara secara umum. Pada tahun 2015 tercatat $18,05 \% \quad(24.530$ jiwa $)$ penduduk Kabupaten Nias hidup di bawah garis kemiskinan. Sedangkan Sumatera Utara secara umum hanya 10,53\% (1.463.660 jiwa). Kondisi ini menunjukkan bahwa secara umum tingkat kesejahteraan penduduk Kabupaten Nias di bawah ratarata.

Begitu juga halnya dengan Indeks Pembangunan Manusia (IPM) yang mampu mencerminkan status kemampuan dasar (basic capabilites) penduduk, yakni; umur panjang dan kesehatan, pengetahuan 
dan keterampilan, dan akses terhadap sumber daya yang dibutuhkan untuk mencapai standar hidup layak. Pada tahun 2015 IPM Kabupaten Nias masih kategori rendah (IPM < 60) dengan nilai 58,85. Angka ini cukup jauh bila dibandingkan dengan rata-rata IPM Sumatera Utara tahun 2015 dengan nilai 69,51 (kategori sedang).

Berdasarkan fakta dan data di atas dibutuhkan upaya yang lebih keras serta sinergi antara semua pihak dalam meningkatkan pembangunan desa di Kabupaten Nias. Sebagaimana paradigma baru pembangunan perdesaan, maka konsekuensi yang harus ditempuh adalah setiap pemimpin di desa wajib meningkatkan kapasitas diri dan mengembangkan jaringan agar mampu bersaing dan sejajar dengan daerah lain. Rip dalam Leeuwis (2009) mengatakan bahwa dalam membangun sebuah komunitas sangat perlu membangun hubungan dan jaringan dalam gagasan baru atau yang sering disebut 'penjajaran'.

Masing-masing desa mempunyai keunggulan-keunggulan tersendiri dilihat dari bidang-bidang yang berbeda. Oleh karena itu, penting menciptakan hubungan yang efektif di antara pengaturan teknologi, sumber daya manusia dan pengorganisasian sosial. Kepala desa harus mampu mengerahkan kreativitas dan mendapatkan gagasan baru yang dapat dimanfaatkan untuk membentuk hubungan dengan desa-desa yang lain. Jika sebelumnya ikatan yang ada antara desa yang satu dengan desa yang lainnya masih lemah (lemah dalam hal kurangnya kontak, jarak, kualitas hubungan, dan daya tahan), maka dengan pengonsolidasian hubungan dan membangun hubungan yang efektif dalam jaringan akan tercipta hubungan yang kuat. Hal ini terlihat dari arus informasi yang mengalir dan dipertukarkan dalam jaringan.

Dampak pelaksanaan UU Desa juga sangat terasa pada desa-desa di wilayah Pemerintah Kabupaten Nias. Dua tahun pasca implementasi UU Desa sejak tahun
2015, dimana kewenangan yang besar dan dukungan dana yang cukup memadai dikelola secara mandiri oleh desa, pola dan aktivitas komunikasi aparatur desa (secara khusus kepala desa) berubah secara signifikan. Ada upaya-upaya untuk mencari informasi dari berbagai pihak dan juga dari kepala desa-kepala desa yang lain dalam lingkup Pemerintah Kabupaten Nias.

Artikel ini lebih lanjut akan membahas dan menjawab pertanyaan bagaimana jaringan komunikasi Kepala Desa di Kabupaten Nias memainkan peran dalam pertukaran informasi dan mendorong inovasi program pembangunan di Kabupaten Nias? Tujuan penelitian ini adalah untuk menganalisis arus informasi yang dipertukarkan antar kepala desa dan menganalisis struktur jaringan komunikasi kepala desa di Kabupaten Nias. Adapun manfaat dari penelitian ini adalah memberikan gambaran jaringan komunikasi pemerintah desa di Kabupaten Nias, untuk mengembangkan inovasi pembangunan berbasis karakteristik kepemimpinan desa dan karakteristik tipologi wilayah desa, dan memberikan saran dan sumbangan pemikiran kepada Pemerintah Kabupaten Nias untuk mendorong percepatan inovasi pembangunan perdesaan dengan memaksimalkan jaringan komunikasi pemerintah desa yang ada dan memaksimalkan potensi opinion leader dalam jaringan.

\section{LANDASAN KONSEP}

\section{Teori Jaringan Komunikasi}

Littletjohn \& Foss (2009) mengatakan bahwa jaringan adalah "susunan sosial yang diciptakan oleh komunikasi antar individu dan kelompok". Dalam pandangan ini dipahami bahwa tidak ada seorang pun yang tidak berkomunikasi dalam sebuah kelompok atau komunitas tertentu. Saat manusia saling berkomunikasi dengan sendirinya 
tercipta mata rantai yang merupakan sebuah pola jaringan. Pola hubungan dalam jaringan menghasilkan struktur tertentu dan setiap aktor menempati posisi tertentu dalam struktur jaringan (Borgatti \& Halgin, 2011).

Dalam bidang ilmu sosial terdapat tiga jenis jaringan (Kadushin, 2004), yaitu jaringan ego-sentris (ego-centric), sosiosentris (socio-centric) dan sistem-terbuka (open-system). Jaringan ego-sentris adalah jaringan yang terhubung dengan aktor (node) tunggal atau individu, misalnya ialah seseorang dengan seorang teman baiknya atau sebuah organisasi dengan organisasi lainnya. Dalam jaringan egosentris yang paling penting untuk diketahui ialah tentang keterkaitan (connections) diantara individu atau organisasi.

$$
\text { Marin \& Wellman }
$$
mendefinisikan jaringan sosial sebagai: "seperangkat node (aktor) sosial yang relevan dihubungkan oleh satu atau lebih hubungan". Node (aktor) atau anggota jaringan adalah unit yang dihubungkan oleh pola interaksi tertentu. Dalam perspektif komunikasi, Monge \& Contractor (2003) mendefinisikan jaringan komunikasi sebagai: "Pola kontak antara mitra komunikasi yang dibuat transmisi dan pertukaran pesan melalui ruang dan waktu". Definisi jaringan komunikasi ini menekankan bahwa antara satu aktor dengan aktor lainnya dihubungkan melalui sebuah pesan. Frasa 'pesan' dalam hal ini dielaborasi lebih lanjut oleh Uddin \& Hossain (2013), meliputi berbagai hal seperti data, informasi, pengetahuan, gambar atau simbol yang dapat diciptakan oleh anggota jaringan dan yang dapat mengalir dari satu aktor ke aktor lainnya dalam jaringan.

Individu dalam sebuah sistem mungkin lebih memilih menghubungi orang-orang tertentu dan mengabaikan orang lain. Interaksi dimana seseorang saling bertukar informasi dengan orang lain merupakan inti dari perilaku manusia (Eriyanto, 2014).
Berdasarkan uraian di atas, maka terlihat dengan jelas bahwa gagasan struktural dasar dari teori jaringan komunikasi adalah keterkaitan (connectedness) yaitu gagasan bahwa ada pola komunikasi yang cukup stabil antar individu (Littlejohn \& Foss, 2011). Individu-individu yang saling berkomunikasi terhubung ke dalam kelompok-kelompok yang selanjutnya saling terhubung dalam keselurahan jaringan melalui pesan atau arus informasi. Keterkaitan dalam jaringan dapat berupa; pertama, jaringan pribadi (personal networks) yaitu hubungan dimana setiap orang memiliki susunan hubungan yang khusus dengan orang lain dalam organisasi. Kedua, jaringan kelompok (group networks) yaitu bahwa organisasi merupakan kumpulan dari beberapa kelompok dan kelompok-kelompok tersebut saling berkomunikasi dengan kelompok yang lain. Ketiga, jaringan organisasi (organizational networks) yaitu hubungan komunikasi yang terjadi antara beberapa organisasi. Keempat adalah jaringan global (global network) merupakan sebuah jaringan kompleks.

Hubungan antara individu dengan individu lainnya, kelompok dengan kelompok lainnya dan organisasi dengan organisasi lainnya terdapat mata rantai (link). Mata rantai dapat mendefinisikan sebuah peranan jaringan (network role) tertentu, yang berarti bahwa mereka menghubungkan kelompok-kelompok dalam cara-cara tertentu (Littlejohn \& Foss, 2011). Peran jaringan menentukan cara bagaimana aktor sosial (individu, kelompok, atau organisasi) terhubung satu sama lain. Hal ini seperti yang katakan oleh Miller bahwa selain mempertimbangkan karakteristik dari jaringan secara keseluruhan (isi, modus, dan kepadatan/density) dan mempertimbangkan keterhubungan jaringan (strength, symmetry, and multiplexity) kemunculan jaringan komunikasi juga harus mempertimbangkan peranan jaringan (Miller, 2012). 
Ada tujuh peranan aktor dalam suatu jaringan komunikasi Pace \& Faules (2002), yaitu: 1) Klik (clique). Klik adalah sebuah kelompok individu yang paling sedikit separuh dari kontaknya merupakan hubungan dengan anggota-anggota lainnya. Sebuah klik terbentuk bila lebih dari separuh komunikasi anggotaanggotanya adalah komunikasi dengan sesama anggota, bila setiap anggota dihubungkan dengan semua anggota lainnya dan bila tidak ada satu hubungan pun atau seorang anggota pun yang dapat dihilangkan sehingga mengakibatkan anggota kelompok terpecah; 2) Penyendiri (isolate). Penyendiri adalah mereka yang hanya melakukan sedikit bahkan tidak melakukan kontak dengan anggota kelompok lain; 3) Jembatan (bridge). Jembatan adalah seorang anggota klik yang memiliki sejumlah kontak yang menonjol dalam kontak antar kelompok, juga menjalin kontak dengan anggota klik lain; 4) Penghubung (liaison). Penghubung adalah orang yang menghubungkan atau mengaitkan dua klik atau lebih tetapi ia bukan anggota salah satu kelompok yang dihubungkan tersebut; 5) Penjaga gawang (gatekeeper). Gatekeeper adalah orang yang secara strategis ditempatkan dalam jaringan agar dapat melakukan pengendalian atas pesan apa yang akan disebarkan melalui sistem tersebut; 6) Pemimpin pendapat (opinion leader). Opinion Leader adalah orang tanpa jabatan formal dalam semua sistem sosial, yang membimbing pendapat dan memengaruhi orang-orang dalam keputusan mereka; 7) Kosmopolit (cosmopolite). Seorang Kosmopolit adalah individu yang melakukan kontak dengan dunia luar, dengan individu-individu di luar organisasi.

\section{Analisis Jaringan Komunikasi}

Jaringan komunikasi dianalisis dengan menerapkan seperangkat hubungan ke dalam seperangkat entitas yang sudah diindentifikasi. Monge \& Contractor (2003) menjelaskan bahwa analisis jaringan komunikasi mengidentifikasi entitas sebagai aktor yang tergabung dalam satu atau lebih kelompok dan menerapkan satu atau lebih hubungan komunikasi.

Scott (2000) juga menjelaskan bahwa hubungan (relation) bukan sifat dari aktor, tetapi sistem dari aktor, hubungan ini menghubungkan kedua belah pihak dari aktor yang satu ke aktor yang lain ke dalam sebuah sistem hubungan yang lebih besar. Dengan penelitian berfokus pada hubungan atau relasi maka data yang digunakan adalah data relasional, dimana hubungan dianggap mengekspresikan hubungan yang terjadi di antara aktor. Analisis jaringan komunikasi dibangun atas dasar seperangkat asumsi Wasserman \& Faust (1994), yakni: Aktor dan tindakan hubungan mereka adalah interdependen, bukan independen, dengan aktor-aktor lainnya. Hubungan (ties) antar aktor dilihat sebagai saluran untuk menransfer atau mengalirkan berbagai jenis sumber.

\section{METODE PENELITIAN}

Pendekatan yang digunakan dalam penelitian ini adalah deskriptif kuantitatif. Populasi penelitian adalah seluruh kepala desa di Kabupaten Nias yang terdiri dari 170 orang yang tersebar dalam 10 Kecamatan. Karena metode analisis jaringan fokus pada hubungan antara para aktor, maka aktor tidak dapat diambil secara bebas untuk dijadikan sebagai objek pengamatan (sampel). Jika salah satu aktor telah dipilih untuk diamati maka konsekuensinya ialah bahwa harus diamati setiap aktor kepada siapa ia memiliki hubungan (Hanneman \& Riddle, 2005). Hal ini dimaksudkan karena: (1) Jaringan komunikasi berpretensi untuk memetakan posisi masing-masing aktor; dan (2) Penelitian jaringan komunikasi menggambarkan relasi antara satu aktor dengan aktor lain secara lengkap sehingga menggambarkan jaringan yang sesungguhnya (Eriyanto, 2014). Dengan 
demikian sedikit berbeda dengan penelitian kuantitatif lainnya, pada penelitian jaringan komunikasi dapat menggunakan teknik sampel bola salju (snowball sampling). Tahapan pertama yang perlu dilakukan ialah mengidentifikasi orang yang dianggap sebagai focal actor (Hanneman \& Riddle, 2005). Kemudian aktor ini diminta untuk menyebutkan beberapa nama dari aktor lain yang memiliki hubungan dengannya. Selanjutnya nama-nama yang telah disebut oleh focal actor juga diminta untuk menyebutkan nama-nama aktor lain yang memiliki hubungan dengan mereka. Proses ini terus berlanjut hingga tidak ada lagi aktor yang teridentifikasi. Maka dari proses tersebut ditemukan 105 sampel sebagai responden. Metode pengumpulan data ialah dengan menggunakan kuesioner. Tahapan proses analisis data dalam penelitian ini: 1) membuat data relasional; 2) analisis sosiometri, dan 3) analisis jaringan.

\section{HASIL PENELITIAN DAN PEMBAHASAN}

\section{Arus Informasi dalam Jaringan}

Merujuk pada transaksional isi yang dipertukarkan oleh aktor sosial sebagaimana dikemukakan oleh Tichy, Tushman \& Fombrun (1979) ada empat jenis transaksional isi pesan yang ditransmisikan dan dipertukarkan, yaitu pertukaran pengaruh, kekuasaan, informasi, dan barang/jasa. Dengan menggunakan empat jenis transaksional isi dimaksud di atas, maka diidentifikasi bentuk isi pesan dalam jaringan komunikasi kepala di Kabupaten Nias, sebagai berikut: 1) Pertukaran pengaruh. Isi pesan komunikasi yang masuk dalam kategori pertukaran pengaruh ialah: membangun persahabatan dan saling bertukar pengalaman di antara kepala desa. Pertukaran pesan ini umumnya dilakukan oleh para kepala desa baru kepada kepala desa yang lain terutama kepada yang sudah senior; 2) Pertukaran kekuasaan. Pertukaran isi pesan tentang kekuasaan dalam jaringan komunikasi kepala desa ialah; konsolidasi pembentukan wadah atau organisasi kepala desa. Isi pesan ini sering dilakukan oleh beberapa kepala desa senior dan memiliki pengaruh kepada kepala desa lainnya. Salah satu harapan besar yang digagas oleh beberapa kepala desa di Kabupaten Nias adalah terbentuknya satu wadah resmi yang menaungi seluruh kepala desa dan menjadi tempat untuk berbagi informasi tentang kesuksesan pelaksanaan pembangunan; 3)

Pertukaran informasi. Isi pesan tentang pertukaran informasi dibagi dalam lima kelompok besar yaitu: pesan tentang tata kelola pemerintahan desa, teknis pembangunan di desa, penguatan organisasi desa, peraturan perundangundangan dan gabungan beberapa isi pesan; 4) Pertukaran barang/jasa. Isi pesan komunikasi yang masuk dalam kategori pertukaran barang/jasa ialahdiskusi tentang pengadaan barang/jasa di desa dan diskusi tentang permasalahan pengangkutan barang di daerah-daerah terisolir.

Dari 449 hubungan yang terjadi, maka isi pesan yang paling banyak didiskusikan adalah: a) Diskusi tentang pengelolaan dana desa sebanyak 127 kali $(27,6 \%)$; b) Diskusi tentang penyelesaian masalah pembangunan di desa sebanyak 36 kali (8\%); c) Gabungan antara diskusi pengelolaan dana desa dan penyelesaian masalah di desa sebanyak 33 kali $(7,3 \%)$; d) Diskusi tentang pengelolaan tata administrasi desa sebanyak 32 kali $(7,1$ $\%)$; e) Diskusi tentang tata kelola pemerintahan desa sebanyak 32 kali $(7,1$ $\%)$; f) Diskusi tentang pembuatan SPJ pengelolaan dana desa sebanyak 30 kali $(6,7 \%) ; \mathrm{g})$ Diskusi tentang integrasi pembangunan di desa sebanyak 28 kali $(6,2 \%) ; 8)$ diskusi tentang adminitrasi keuangan desa sebanyak 15 kali $(3,3 \%)$; h) Diskusi tentang konsolidasi pembentukan wadah organisasi kepala desa yang resmi sebanyak 14 kali $(3,1 \%)$; 
dan i) Sisanya sebanyak 105 kali $(23,39$

$\%)$.

Tabel 1

Daftar Kecamatan di Kabupaten Nias

\begin{tabular}{clrc}
\hline No & \multicolumn{1}{c}{ Kecamatan } & $\begin{array}{c}\text { Luas Wilayah } \\
\text { (Ha) }\end{array}$ & Jumlah Desa \\
\hline 1 & Idanogawo & $13.865,55$ & 28 \\
2 & Bawolato & $20.445,80$ & 25 \\
3 & Ulugawo & $6.596,63$ & 14 \\
4 & Gido & $11.005,67$ & 21 \\
5 & Mau & $6.118,77$ & 11 \\
6 & Somolo-molo & $4.485,39$ & 11 \\
7 & Hiliduho & $6.507,63$ & 16 \\
8 & Hiliserangkai & $6.191,60$ & 15 \\
9 & Botomuzoi & $5.998,29$ & 18 \\
10 & Sogaeadu & $4.126,99$ & 11 \\
& Luas Daratan & $85.342,32$ & \\
& Luas Laut & $58.522,00$ & \\
& Jumlah Total & $143.864,32$ & 170 \\
\hline
\end{tabular}

Sumber: Nias Dalam Angka Tahun 2016.

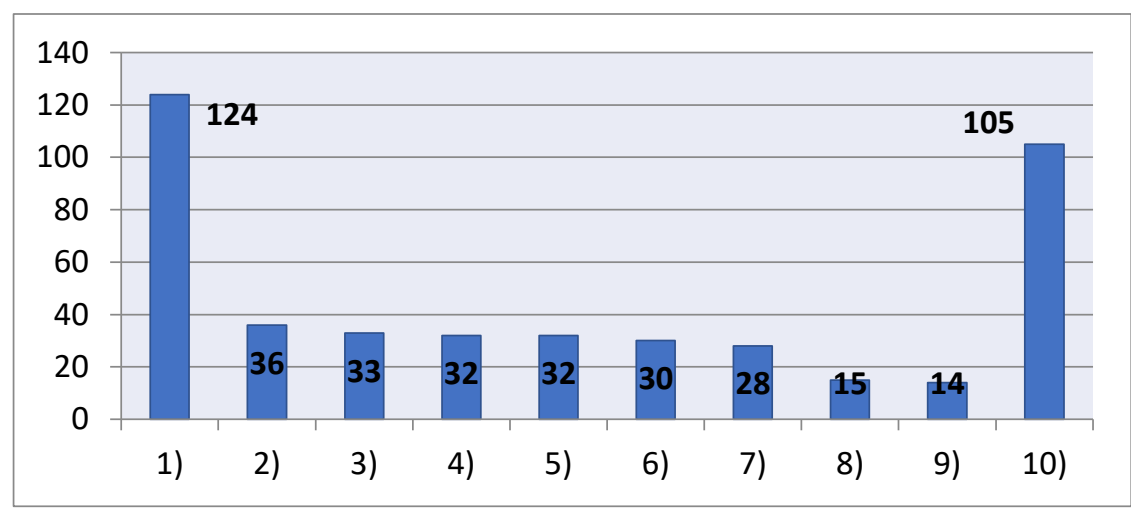

Sumber: Hasil Analisis Data Primer, 2017

Gambar 1. Frekuensi Isi Pesan dalam Jaringan

\section{Dasar Ikatan Hubungan}

Adapun sumber-sumber ikatan hubungan komunikasi dalam jaringan komunikasi kepala di Kabupaten Nias, sebagai berikut: 1) Ikatan persahabatan. Mayoritas kepala desa di Kabupaten Nias menjalin hubungan komunikasi karena didasari oleh ikatan persahabatan; 2)

Ikatan bisnis. Beberapa kepala desa juga menjalin komunikasi karena didasari oleh ikatan bisnis; 3) Ikatan berdasarkan asosiasi atau afiliasi. Berafiliasi dalam satu lembaga sekolah karena mereka samasama guru (honorer) dan berafiliasi dalam sebuah gereja tertentu; 4) Ikatan perilaku. Dilihat dari aspek perilaku, beberapa kepala desa menjalin komunikasi karena wilayah desa mereka bertetangga sehingga lebih mudah dan cepat untuk menjalin komunikasi; 5) Ikatan berdasarkan pergerakan geografis. Dilihat dari aspek geografis terdapat banyak kepala desa yang menjalin hubungan karena mereka berada dalam satu wilayah kecamatan, desa tetangga atau sama-sama berada dalam wilayah terisolir; 6) Ikatan berdasarkan perubahan status. Beberapa kepala desa menjalin hubungan karena mereka mengalami perubahan status dari warga biasa menjadi kepala desa; 7) Ikatan berdasarkan hubungan fisik. Beberapa kepala desa menjalin hubungan karena 
kedua desa berbatasan sehingga mereka dituntut untuk merencanakan programprogram dan kegiatan pembangunan yang terintegrasi dan juga kerjasama antar desa untuk mewujudkan program desa percontohan; 8) Ikatan formal. Dilihat dari aspek ikatan formal terdapat beberapa kepala desa terlibat dalam struktur organisasi yang sama seperti lembaga swadaya masyarakat; 9) Ikatan biologis. Beberapa kepala desa menjalin hubungan komunikasi karena adanya hubungan kekeluargaan.

Dari 449 ikatan, ikatan yang paling menonjol adalah ikatan hubungan persahabatan sebanyak 221 hubungan (49,2 \%), di posisi kedua adalah ikatan hubungan karena desa tetangga sebanyak 137 hubungan $(30,5 \%)$, di posisi ketiga adalah ikatan hubungan karena berada dalam satu wilayah kecamatan sebanyak 28 hubungan $(6,2 \%)$, di posisi keempat adalah ikatan hubungan karena ada hubungan keluarga sebanyak 12 hubungan $(2,7 \%)$, dan sisanya di bawah 10 hubungan dengan total 51 hubungan $(11,3$ $\%)$.

\section{Jaringan Komunikasi}

Analisis jaringan komunikasi yang dilakukan terhadap 105 kepala desa di Kabupaten Nias difokuskan pada arus informasi atau pesan yang terjadi di antara kepala desa untuk inovasi program pembangunan. Arus informasi atau pesan menggambarkan hubungan antar-satu aktor dengan aktor yang lain baik dengan cara menghubungi aktor lain atau dihubungi oleh aktor lain. Temuan penelitian menunjukkan bahwa jumlah hubungan yang terjadi di antara 105 kepala desa adalah 449 relasi. Jumlah ini masih sangat kecil bila dibandingkan dengan jumlah kemungkinan hubungan yang terjadi yaitu $\{[105(105-1)]=10.920\}$ hubungan.

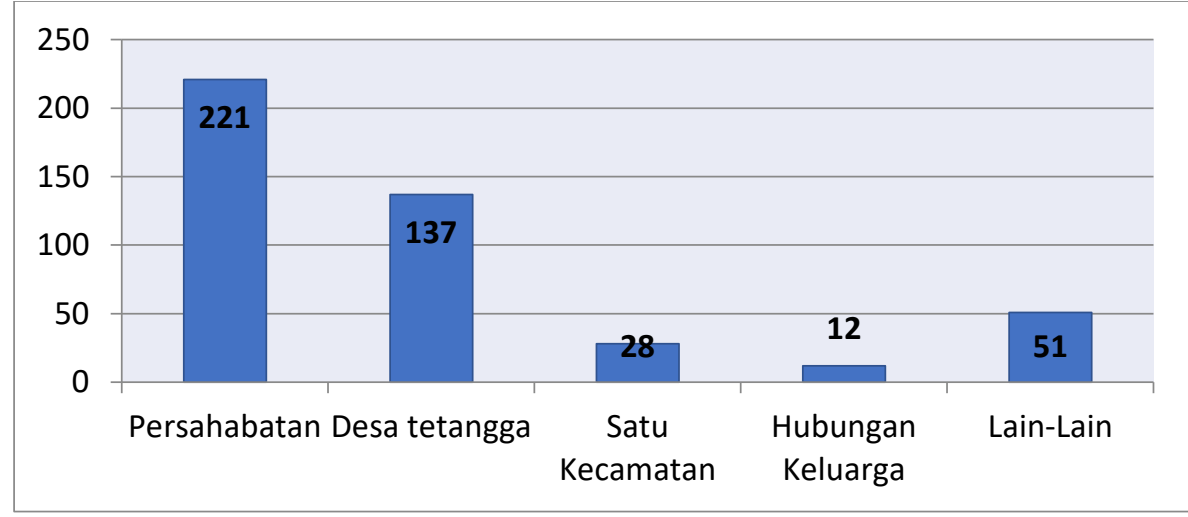

Sumber: Hasil Analisis Data Primer, 2017

Gambar 2. Frekuensi Ikatan Hubungan dalam Jaringan

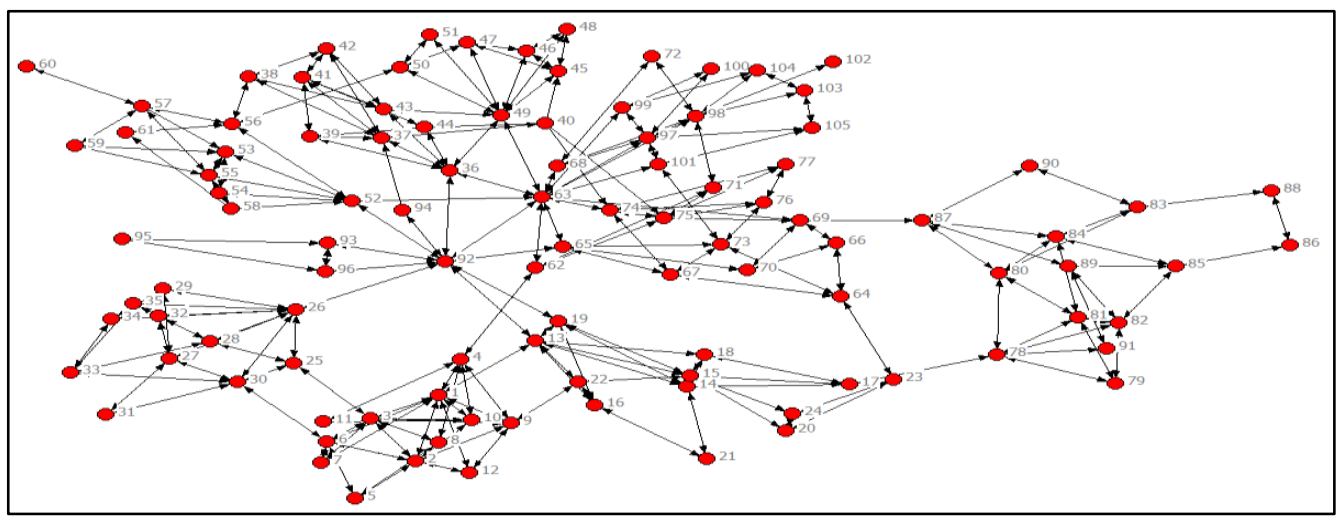

Sumber: Hasil Analisis, 2017

Gambar 3. Sosiogram Pola Jaringan Komunikasi Kepala Desa di Kabupaten Nias 
Tabel 2

Struktur Jaringan Komunikasi Kepala Desa

\begin{tabular}{clc}
\hline No. & \multicolumn{1}{c}{ Parameter } & Nilai \\
\hline 1 & Jumlah Aktor (Kepala Desa) & 105 \\
2 & Jumlah Hubungan (Ties) & 449 \\
3 & Density & 0,041 \\
4 & Dyad Reciprocity & 0,952 \\
5 & Diameter & 9 \\
6 & Average Distance & 4,248 \\
7 & Closure & 0,308 \\
\hline
\end{tabular}

Sumber: Hasil Analisis Data Primer, 2017

Tabel 3

Kepadatan Jaringan Klik

\begin{tabular}{clc}
\hline Klik & Kecamatan & Kepadatan \\
\hline 1 & Hiliduho & 0,400 \\
2 & Botomuzoi & 0,439 \\
3 & Hiliserangkai & 0,348 \\
4 & Bawolato & 0,286 \\
5 & Somolo-Molo & 0,550 \\
6 & Idanogawo & 0,233 \\
7 & Ma'u & 0,333 \\
8 & Gido & 0,472 \\
9 & Sogae'adu & 0,619 \\
10 & Ulugawo & 0,361 \\
\hline
\end{tabular}

Sumber: Hasil Analisis Data Primer, 2017

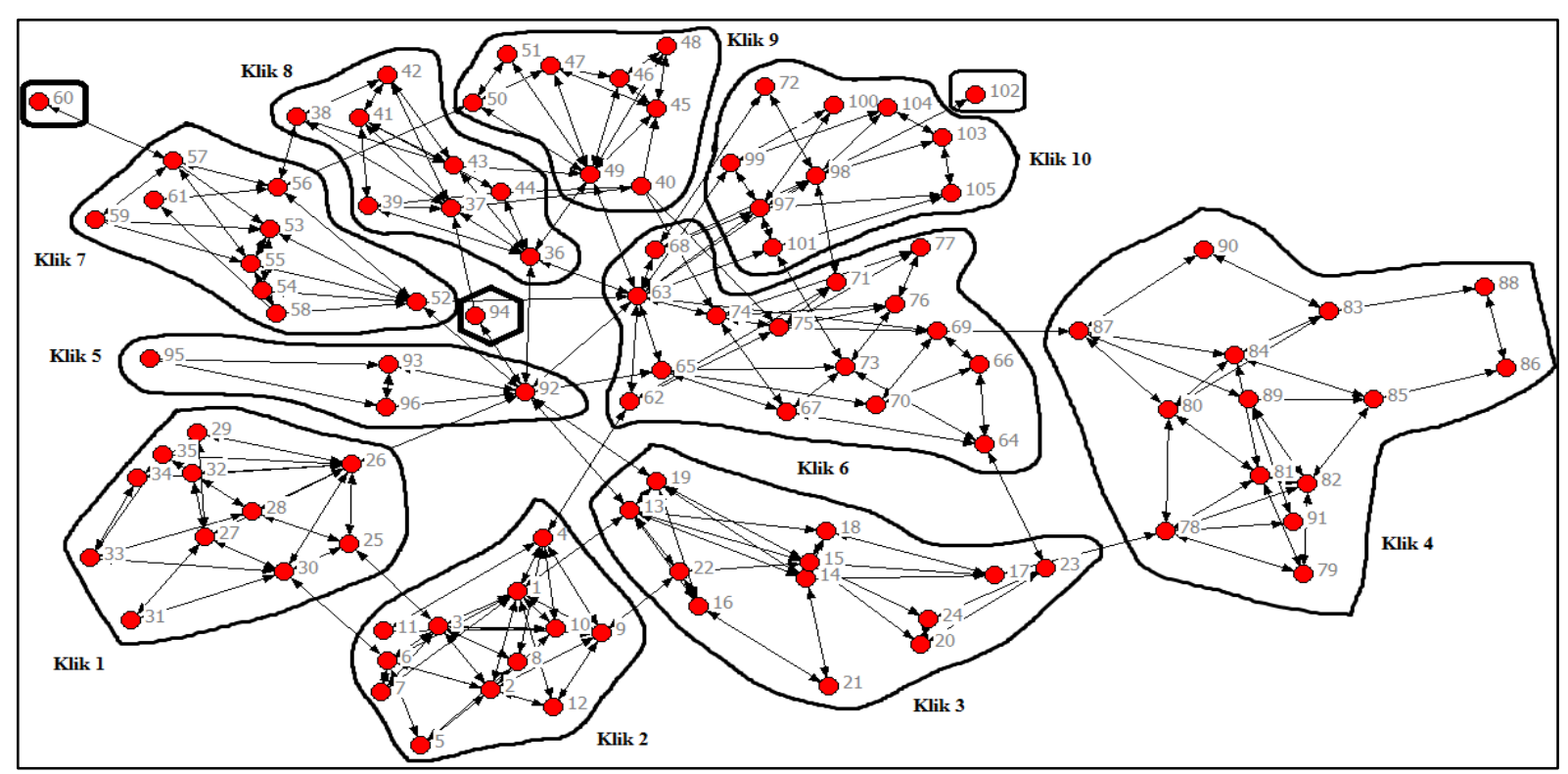

Sumber: Hasil Analisis, 2017

Gambar 4.Klik Jaringan Komunikasi Kepala Desa di Kabupaten Nias.

\section{Identifikasi Sub Grup dalam Jaringan}

Berdasarkan hasil analisis seperti yang terlihat dalam Gambar 3 . Menunjukkan bahwa 105 kepala desa secara keseluruhan terhubung satu sama lain tanpa ada kelompok yang memisahkan diri. Artinya bahwa jaringan komunikasi kepala desa di Kabupaten Nias berada dalam satu komponen. Sedangkan bila ditinjau dari pengelompokkan berdasarkan klik, maka jaringan komunikasi kepala desa di Kabupaten Nias ada 10 klik berbasis kecamatan seperti yang tampak dalam Tabel 3. 


\section{Sentralitas Aktor}

Sentralitas aktor adalah soal posisi aktor dalam jaringan, yakni aktor-aktor yang menonjol dan mempunyai pengaruh.

1. Sentralitas tingkatan merupakan gambaran seberapa sering seorang aktor dihubungi (in degree) dan seberapa sering pula ia menghubungi (out degree), lihat Tabel 4.

2. Sentralitas kedekatan merupakan gambaran seberapa dekat aktor dengan semua aktor lain dalam jaringan, lihat Tabel 5.

3. Sentralitas keperantaraan menggambarkan tingkatan dimana seorang aktor berperan sebagai perantara dari hubungan antar actor, lihat Tabel 6.

\section{Aktor Kunci dalam Jaringan}

Hasil analisis menunjukkan bahwa dari 10 besar kepala desa dengan nilai sentralitas tingkatan, kedekatan, dan keperantaraan terdapat dua orang kepala desa yang selalu konsisten baik dari sisi popularitas dalam jaringan, kedekatan dengan aktor lain dan kemampuan memperantarai kepala desa-kepala desa lain. Mereka adalah Kepala Desa Saiwahili Hili'adulo Kecamatan Idanogawo atas nama Ediyanus Zai (63) dan Kepala Desa Sifaoroasi Kecamatan Somolo-Molo atas nama Sabayuti Gulo (92). Mereka berdua adalah kepala desa yang selalu konsisten dengan nilai sentralitas tingkatan, sentralitas kedekatan, dan sentralitas keperantaraan yang tinggi.

Tabel 4

Nilai Sentralitas Tingkatan (Degree Centrality)

\begin{tabular}{|c|c|c|c|c|c|c|}
\hline \multirow[b]{2}{*}{ NO. } & \multirow[b]{2}{*}{ AKTOR (ID) } & \multicolumn{3}{|c|}{ DEGREE } & \multicolumn{2}{|c|}{ DEGREE (NORMAL) } \\
\hline & & $\begin{array}{c}\text { OUT } \\
\text { DEGREE }\end{array}$ & $\begin{array}{c}I N \\
\text { DEGREE }\end{array}$ & $\begin{array}{c}\text { TOTAL } \\
\text { DEGREE }\end{array}$ & $\begin{array}{c}\text { OUT } \\
\text { DEGREE }\end{array}$ & $\begin{array}{c}I N \\
\text { DEGREE }\end{array}$ \\
\hline 1 & EDIYANUS ZAI (63) & 36 & 34 & 70 & 0,086 & 0,081 \\
\hline 2 & LIDASOKHI MENDROFA (26) & 30 & 29 & 59 & 0,072 & 0,069 \\
\hline 3 & SABAYUTI GULO (92) & 29 & 27 & 56 & 0,069 & 0,065 \\
\hline 4 & ANWAR LASE (1) & 23 & 25 & 48 & 0,055 & 0,060 \\
\hline 5 & AMOLISI GULO (37) & 24 & 24 & 48 & 0,057 & 0,057 \\
\hline 6 & MEZIARO HALAWA (2) & 24 & 21 & 45 & 0,057 & 0,050 \\
\hline 7 & YANUARMAN BUAYA (49) & 22 & 22 & 44 & 0,053 & 0,053 \\
\hline 8 & REZEKI WARUWU (3) & 22 & 21 & 43 & 0,053 & 0,050 \\
\hline 9 & ODIAMAN LAOLI (36) & 19 & 22 & 41 & 0,045 & 0,053 \\
\hline 10 & OTONIUS LAIA (97) & 21 & 19 & 40 & 0,050 & 0,045 \\
\hline
\end{tabular}

Sumber: Hasil Analisis Data Primer, 2017 
Tabel 5

Nilai Sentralitas Kedekatan (Closeness Centrality)

\begin{tabular}{llll}
\hline & \multicolumn{2}{c}{ Nilai Sentralitas Kedekatan (Closeness Centrality) } \\
\multirow{2}{*}{ NO. } & \multicolumn{1}{c}{ AKTOR (ID) } & \multicolumn{2}{c}{ CLOSENESS } \\
CLOSENESS & CLOSENESS \\
\hline 1 & EDIYANUS ZAI (63) & 0,377 & 0,380 \\
2 & SABAYUTI GULO (92) & 0,365 & 0,366 \\
3 & ODIAMAN LAOLI (36) & 0,322 & 0,323 \\
4 & OTENIELI GULO (52) & 0,321 & 0,323 \\
5 & OGAMOTA MENDROFA (13) & 0,317 & 0,318 \\
6 & EKA KRISDESNAWATI (65) & 0,311 & 0,313 \\
7 & ASA'ARO ZAI (69) & 0,310 & 0,313 \\
8 & AGUSTINUS MENDROFA (19) & 0,304 & 0,305 \\
9 & DENIUS GEA (62) & 0,299 & 0,301 \\
10 & YANUARMAN BUAYA (49) & 0,297 & 0,299
\end{tabular}

Sumber: Hasil Analisis Data Primer, 2017

Tabel 6

Nilai Sentralitas Keperantaraan (Betweenness Centrality)

\begin{tabular}{clr}
\hline NO. & \multicolumn{1}{c}{ AKTOR (ID) } & BETWEENNESS \\
1 & EDIYANUS ZAI (63) & 4573,675 \\
2 & SABAYUTI GULO (92) & 4117,312 \\
3 & ASA'ARO ZAI (69) & 2043,340 \\
4 & LIDASOKHI MENDROFA (26) & 1781,775 \\
5 & OGAMOTA MENDROFA (13) & 1721,409 \\
6 & TABOSIAGO LAFAU (87) & 1694,592 \\
7 & OTENIELI GULO (52) & 1623,477 \\
8 & ODIAMAN LAOLI (36) & 1228,517 \\
9 & YANUARMAN BUAYA (49) & 1190,769 \\
10 & DENIUS GEA (62) & 942,716
\end{tabular}

Sumber: Hasil Analisis Data Primer, 2017

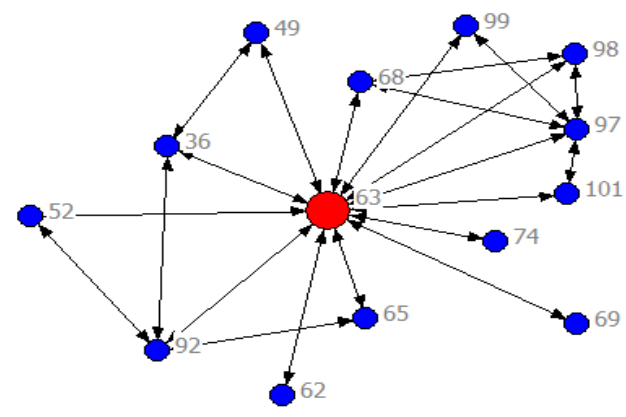

Ediyanus Zai (63)

Degree: 70

Closenses: 0,377
Betweennes:4573,675

Density: 0,115
Sabayuti Gulo (92)

Degree: 59

Closeness: 0,365

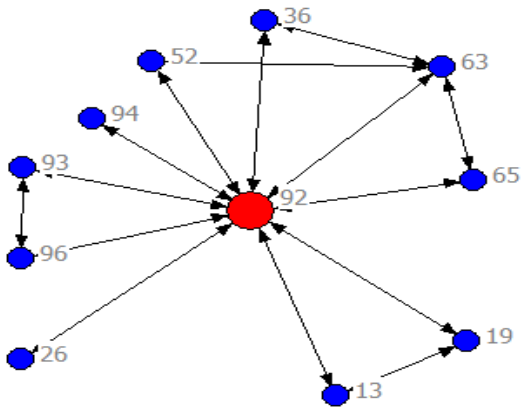

Betweennes:4117,312

Density: 0,111

Sumber: Hasil Analisis Data Primer, 2017

Gambar 5. Jaringan Ego Aktor Kunci 


\section{PENUTUP}

\section{Simpulan}

Implikasi dari penelitian ini terlihat bahwa jaringan komunikasi kepala desa di Kabupaten Nias belum maksimal dalam memainkan peran untuk mendorong inovasi program pembangunan. Para kepala desa masih disibukkan dengan pertukaran informasi yang sifatnya administratif sedangkan pertukaran informasi yang bermuatan inovasi program pembangunan masih sangat minim.

Di sisi lain, kekuatan atau kepadatan jaringan komunikasi yang terbentuk dalam jaringan komunikasi kepala desa di Kabupaten Nias secara keseluruhan masih sangat rendah. Justru intensitas komunikasi kepala desa di Kabupaten Nias terjadi dalam klik-klik berbasis kecamatan. Dampak dari kualitas komunikasi seperti ini ialah terbatasnya informasi dan inovasi.

Secara sadar atau tidak sadar, kepala desa membatasi diri dalam memperoleh informasi atau inovasi dari luar. Hal ini sangat bertentangan dengan upaya agar para kepala desa mampu menyejajarkan diri dengan desa yang lain bila para kepala desa membatasi diri untuk berkomunikasi hanya dengan kepala desa dalam lingkup kecamatannya saja.

Implikasi lain dari penelitian ini ialah adanya kecenderungan para kepala desa menjadikan beberapa orang tertentu saja sebagai sumber informasi utama. Hal ini memang disebabkan karena jaringan yang lemah dan informasi yang diterima kurang beragam dan ruang lingkup komunikasi dibatasi oleh sekat-sekat tertentu. Kondisi ini menghambat pembangunan desa karena bertentangan dengan prinsip-prinsip keterbukaan dan kemandirian dalam informasi.

\section{Saran}

Memaksimalkan peran kepala desakepala desa yang berada di posisi sebagai aktor kunci, opinion leader pada klik dan bridge sebagai aktor utama dalam penyebarluasan

informasi-informasi

pembangunan,

Mendorong terbangunnya jaringan komunikasi kepala desa yang efektif dengan penekanan materi-materi diskusi pada informasi-informasi pembangunan yang substantif dan inovatif. Hal ini bisa dilakukan dengan adanya intervensi oleh pemerintah kecamatan sebagai entitas yang melakukan koordinasi dan kontrol penyelenggaraan pemerintah desa.

Mendorong pengembangan jaringan komunikasi kepala desa di Kabupaten Nias yang dinamis dengan membangun hubungan kerjasama dengan stakeholderstakeholder lain di luar pemerintahan seperti perguruan tinggi, perusahaanperusahaan pengembang teknologi tepat guna dan juga perusahaan-perusahaan pengembang teknologi informasi dan komunikasi untuk mewukudkan desa-desa di Kabupaten Nias sebagai desa inovatif.

\section{DAFTAR PUSTAKA}

Berger, C.R. (2014) Handbook Ilmu Komunikasi. Bandung, Nusamedia.

Borgatti, S.P. \& Halgin, D.S. (2011) On Network Theory. Organization Science. [Online] 22 (5), 1168-1181. Available from: doi:10.1287/orsc.1100.0641.

Eriyanto (2014) Analisis Jaringan Komunikasi Strategi Baru dalam Penelitian Ilmu Komunikasi dan Ilmu Sosial Lainnya. Jakarta, Kencana.

Hanneman, R.A. \& Riddle, M. (2005) Introduction to social network methods. [Online]. Riverside, CA, University of California. Available from: http://faculty.ucr.edu/ hanneman.

Ife, J.W. \& Tesoriero, F. (2008) Community Development: Community Based Alternatives in on Age of Globalisation (Community Development: Alternatif Pengembangan Masyarakat di Era Globalisasi). Yogyakarta, Pustaka Pelajar.

Kadushin, C. (2004) Introduction to Social Network Theory. [Online]. Available from:

http://www.cin.ufpe.br/ rbcp/taia/Kadus 
hin_Concepts.pdf.

Kasali, R. (2016) Kita Hidup dalam Gempuran Urbanisasi. [Online]. 2016. Kompas.com. Available from: http://bisniskeuangan.kompas.com/read/2 016/02/10/052800326/Kita.Hidup.dalam. Gempuran.Urbanisasi.

Katz, N., Lazer, D., Arrow, H. \& Contractor, N. (2004) Network Theory and Small Groups. Small Group Research. [Online] 35 (3), 307-332. Available from: doi:10.1177/1046496404264941.

Leeuwis, C. (2009) Komunikasi untuk Inovasi Pedesaan: Berpikir Kembali tentang Penyuluhan Pertanian (dengan kontribusi dari Anne van den Ban). Yogyakarta, Kanisius.

Littlejohn, S.W. \& Foss, K.A. (2011) Theories of Human Communication. 10th edition. Long Grove, lllinois, Waveland Press, Inc.

Littletjohn, S.W. \& Foss, K.A. (2009) TeoriTeori Komunikasi. Jakarta, Salemba Humanika.

Marin, A. \& Wellman, B. (2011) Social Network Analysis-An Introduction. Thousand Oaks, California, Sage Publication.

Miller, K. (2012) Organizational Communication: Approaches and Processes. Sixth Edit. Wadsworth, Cengage Learning.

Monge, P.R. \& Contractor, N.S. (2003) Theories of Communication Networks. New York, Oxford University Press.

Mustakim, M.Z. (2015) Kepemimpinan Desa. Jakarta, Kementerian Desa PDTT RI.
Nugroho, R. (2015) Policy Making: Membangun Negara Biasa Menjadi Negara Berprestasi. Jakarta, Elex Media Komputindo.

Pace, R.W. \& Faules, D.F. (2002) Komunikasi Organisasi: Strategi Meningkatkan Kinerja Perusahaan. Bandung, Remaja Rosdakarya.

Rogers, E.M. \& Kincaid, D.L. (1981) Communication Networks: Toward a New Paradigm for Research. New York, Free Pres.

Scott, J. (2000) Social Network Analysis: A Handbook. Contemporary Sociology. [Online]. 3 p.208. Available from: doi:10.1370/afm.344.

Severin, W.J. \& Tankard, J.W. (2009) Teori Komunikasi: Sejarah, Metode dan Terapannya di Dalam Media Massa. 5th edition. Jakarta, Kencana Prenada Media Group.

Tichy, N.M., Tushman, M.L. \& Fombrun, C. (1979) Social Network Analysis for Organizations. The Academy of Management Review. [Online] 4 (4), 507. Available from: doi:10.2307/257851.

Uddin, S. \& Hossain, L. (2013) Dyad and Triad Census Analysis of Crisis Communication Network. Social Networking. [Online] 02 (01), 32-41. Available from: doi:10.4236/sn.2013.21004.

Wasserman, S. \& Faust, K. (1994) Social Network Analysis: Methods and Application. Cambridge, Cambridge University Press. 